\title{
End of an elemental era
}

\author{
We reflect on our monthly 'In Your Element' feature that comes to an end in this issue.
}

S ince the launch of Nature Chemistry in April 2009, the last page of each issue of the journal has been occupied by the 'In Your Element' (IYE) column, which has focused each month on a different tile of the periodic table. There are currently 118 known elements, and we also included the two rather special isotopes of hydrogen: deuterium and tritium. This means that the IYE essay in this 120th issue of the journal, on mendelevium, is the final one. With fortuitous timing this feature, which has been running for exactly ten years, is coming to an end during the International Year of the Periodic Table (https://www.iypt2019.org/) and it is somewhat fitting that we end with the element named after the main architect of the table that evolved into the one we use today.

From the very beginning, there has been no set formula for these essays; they are simply intended to be informative and entertaining stories about an element. They gather together a wide variety of snippets, ranging from historical and etymological accounts, to chemical characteristics, to personal anecdotes, and we have learnt a great deal about the periodic table, and its contents, along the way.

With its relatively simple appearance all of the elements catalogued in order of increasing atomic number, arranged in a manner that reflects characteristic trends - it's perhaps easy today to take the periodic table for granted, yet the familiar chart has been painstakingly shaped by the work of many scientists. When Dmitri Mendeleev proposed his early version 150 years ago, he featured the 63 then-known elements, as well as several gaps for others that were still unknown. Although some of those missing elements turned up within a matter of years, the last blank tile of his table was only filled when technetium - a lone radioactive element in the middle of the $d$-block - was created artificially and finally identified in 1937.

Some elements caused classification problems. The noble gases for example of which krypton, neon and xenon were discovered within just weeks of each other had no place at the table for several puzzling years until they were finally given their own column in 1902. Another major adjustment came in the mid-1940s when Glenn Seaborg moved the actinide series below that of the lanthanides. Yet the table as we know it is still not set in stone. The occupancy of group 3 in particular is debated - should lanthanum and actinium, or lutetium and lawrencium, sit

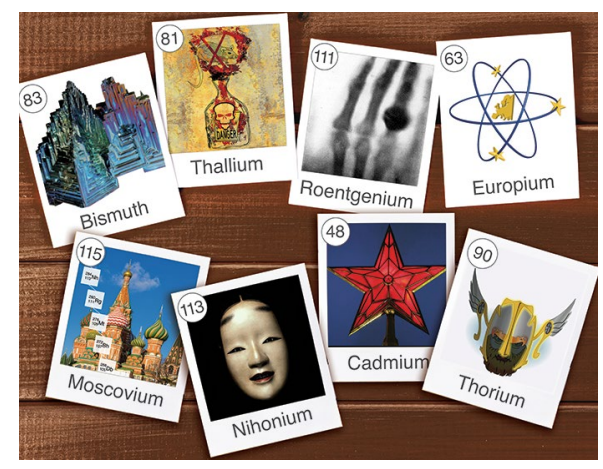

Credit: Thallium, Dorota Nowańska / Alamy; roentgenium, World History Archive / Alamy Stock Photo; moscovium, Loop Images Ltd / Alamy Stock Photo; nihonium, Pacific Press Service / Alamy Stock Photo; cadmium, Mihail Chekalov / Alamy

below scandium and yttrium? Can lawrencium even be considered a $p$-block element?

The rare earths proved to be a trove of discovery quirks. (Despite their name these elements aren't all that rare in the Earth's crust; the most common one, cerium, is nearly as abundant as copper). Johan Gadolin, for example, guessed the existence of a new element, albeit reluctantly as he feared the rare earths were 'becoming far too numerous' - this very element is now known as gadolinium. A blunder caused confusion between two minerals: in 1843 Carl Mosander analysed erbia and terbia in search of two new elements. A mix-up in his samples, however, meant that he isolated erbium from terbia and terbium from erbia; the minerals' names were subsequently swapped.

The IYE articles also feature poetic passages: a description of dysprosium - a curse and a blessing - that is borrowed from that of love in La Traviata; a stanza from a poem by Rudyard Kipling entitled 'Cold iron'; and excerpts from Jules Verne's books in which he had foreseen the use of water as a fuel 'decomposed into its primitive elements', and written in praise of aluminium - a light metal that was once more precious than gold.

There are quite a few unnerving accounts of early uses of $p$-block elements that were curbed when toxicity issues became painfully obvious: phosphorus in matches that plagued workers with a bone necrosis called 'phossy jaw'; mercury causing the neurological disorder now known as 'mad hatter' disease; the ubiquitous use of lead compounds (including one dubbed 'lead sugar'). In contrast, bismuth is a bit of an oddity among the heavy metals owing to its low toxicity. Only two tiles to the left, though, sits thallium - the weapon of choice of an English serial killer nicknamed the 'teacup poisoner', and an element that should perhaps have remained altogether undiscovered.

A number of glowing, radioactive elements also proved dangerously alluring. Initially purported to be a wonder element, radium used to be sprinkled into everything from water to food to cosmetics (presumably making skin glow for all the wrong reasons). Radioactive elements now safely serve a variety of purposes from atomic clocks to geological dating. Some can also be purchased surprisingly easily: americium in smoke detectors and tritium in battery-free luminescent gadgets.

The stories of some of the heavier elements are replete with discovery disputes. The controversies were so fierce that they are referred to as 'transfermium wars' and a special committee, the transfermium working group, was created to adjudicate claims and attribute names. Those elements beyond fermium, at the bottom right corner of the periodic table, are very unstable and cannot be prepared in weighable quantities. Undeterred, scientists have developed special experimental techniques: there is such a thing as one-atomat-a-time chemistry.

At the other end of the spectrum there are elements that have essentially been around forever. Hydrogen and helium, for example, appeared only around 380,000 years after the Big Bang. Oxygen played a key role in the origin and evolution of life and nitrogen is intimately implicated in most matters of life and death. Nickel, iron and sulfur are thought to have been used by early forms of life; today most living organisms rely on iron. Another transition metal, iridium - which incidentally adopts the widest known range of oxidation states (from -3 to +9 ) - can provide clues as to why the dinosaurs died out.

The IYE articles have reflected the depth and breadth of the periodic table. We have thoroughly enjoyed this feature, and hope you have too. This is the end - for now. Element hunters are currently crafting even heavier nuclei, and an IYE essay will be warranted when a few such atoms have fleetingly appeared. Stay tuned!

Published online: 21 February 2019 https://doi.org/10.1038/s41557-019-0231-z 